\title{
Breast Feeding in Developing Countries: Is There a Scope for Improvement
}

\section{Reeta Bora*}

Associate Professor, Neonatology Unit, Assam Medical College, Dibrugarh-786001, Assam, India

\begin{abstract}
The World Health Organisation recommends exclusive breast feeding till six months of age followed by breast feeding along with complementary feeding thereafter for optimal growth of children. Thirteen percent of under five mortality can be averted globally each year by breast feeding alone. Despite recognition of this benefit, rates of exclusive breastfeeding for WHO recommended period is poor, especially in developing countries where the need is most. Several studies have shown that educational interventions significantly increased breastfeeding rates. Structured combined individual and group counselling seems to be the best method of improving breast feeding rates at this time.
\end{abstract}

Keywords: Breast feeding; Developing world; Education

\section{Introduction}

The World Health Organization (WHO) recommends exclusive breast feeding till six months of age followed by breast feeding along with appropriate complementary feeding thereafter for optimal growth of children [1]. Breast feeding is the extension of the natural maternal protection that transitions the newborn from the in utero environment which is otherwise safe to extra uterine life which is at many times full of challenges.

There is a strong evidence that promotion, protection and support of breast feeding is an exceptionally cost effective strategy for improving child survival and reducing burden of childhood diseases specially in developing countries $[2,3]$.

Since the turn of millennium the number of child death has declined significantly from an estimated 11.6 million in 2000 to 7.2 million in 2010 [4]. Of all these deaths more than $13 \%$ of under five mortality can be averted globally per year by breast feeding [5]. No breast feeding as compared to exclusive breast feeding is also associated with $165 \%$ increase in diarrheal diseases in infants between 0-5months of age and $32 \%$ increase of same in 6-11 month old infants [4].

Despite the recognition of causes related to problems of child survival, inequity of child health remains a persistent global problem [6]. Although breast feeding has been recognized as a key determinant of child survival, rates of exclusive breast feeding for WHO recommended period of first six months of life is far from optimal globally. It is more so in developing countries where it is mostly needed. In the developing world, only one out of three children is exclusively breast fed till six months of age [7] although considerable variation in rate exists amongst regions.

In India according to the National family health survey (NFHS3, 2005-2006), exclusive breast feeding (EBF) rate at six month of age is only $46.4 \%$ [8].

Patel et al. [9] in a multicentric prospective cohort study including six low and middle income countries tried to look at incidence and determinants of early initiation of breast feeding (IEB) and exclusive breast feeding (EBF) by 42 days of life. They prospectively collected data from women and their live born enrolled in the Global Network of maternal and Newborn Health Registry between January $1^{\text {st }} 2010$ to December $31^{\text {st }} 2013$ and included woman infant dyads in 106 geographical areas (clusters) at seven research sites in six countries (Kenya, India, Zambia, Pakistan, Guatemala and Argentina). Rates and risk factors for failure to initiate breast feeding were investigated for the entire cohort and rate and risk factors for failure of maintenance of exclusive breast feeding were assessed in sub sample studied at 45 days postpartum. A total of 2,25,495 live born woman infant dyad were included in the study. Among 105563 subjects, rates and determinants of early initiation of exclusive breast feeding and sub study at 42 days postpartum for EBF was assessed. They found the early initiation of breast feeding after delivery was in the range of 70 to $80 \%$ across all areas except in Pakistan where the rate was only around $22 \%$. The rate of exclusive breast feeding on day 42 of life changed from 76 to 99.5 across participating global network sites.

In another study published in 2012, Cai et al. [10] using the global data base of infant and young children feeding, maintained by United Nations Children's Fund, examined estimates from 440 household between 1995 and 2010 and calculated global and regional average of the rate of exclusive breast feeding among infants 0-5 months for the two time points to access the trends. Their trend data suggested that the prevalence of exclusive breast feeding among infants younger than six months of age increased from $33 \%$ in 1995 to $39 \%$ in 2010. The prevalence increased in almost all regions in the developing world, with biggest improvement seen in West and Central Africa where the prevalence doubled from $12 \%$ to $28 \%$, more modest improvements were observed in South East Asia where the increase from 40\% in 1995 to $44 \%$ in 2010 .

Although the scenario is improving, their study highlighted the fact that in spite of the well recognized importance of exclusive breast feeding, the practice is not wide spread in the developing world and increase on the global level is still very modest with much room for improvement. Child nutrition programs worldwide continue to require investments and commitments to improve infant feeding practices in order to have maximum impact on children lives.

*Corresponding author: Reeta Bora, Associate Professor, Neonatology Unit, Assam Medical College, Dibrugarh-786001, Assam, India, Tel: +91 9435394313 ; E-mail: rbora_amc@yahoo.co.in

Received September 29, 2015; Accepted January 05, 2016; Published January 12, 2016

Citation: Bora R (2016) Breast Feeding in Developing Countries: Is There a Scope for Improvement. J Neonatal Biol 5: 208. doi:10.4172/2167-0897.1000208

Copyright: (c) 2016 Bora R. This is an open-access article distributed under the terms of the Creative Commons Attribution License, which permits unrestricted use, distribution, and reproduction in any medium, provided the original author and source are credited. 
A recent WHO report shows that the median coverage of EBF has increased from $26 \%$ in $2000-2005$ to $40 \%$ in 2006-2011 in the 48 countries [11].

The high rate of EBF at 42 days as found by Patil et al. in contrast to Cai et al. can be explained by the fact as mentioned by Patil et al. that their study sites had been part of the Global Network for a number of years and have had participated in a number of trials to improve maternal and child health. As a result of the exposure to maternal a child health initiative, it is likely that the awareness level amongst women, health workers, community opinion leaders regarding importance of early and exclusive breast feeding were high.

Thus different studies highlights the point that the rate of EBF, a key factor for reducing child mortality is still far from ideal and there is potential for breast feeding interventions to reduce inequity in Child mortality [12]. Roberts et al. using available data to estimate the changes in prevalence of exclusive and partial breast feeding in 137 developing countries separately by wealth quintile, have shown that gains in breast feeding coverage care equals across wealth quintiles. Breast feeding does not rely on health infrastructure and does not rely on wealth of person to be taken up and helps to prevent diseases like diarrhea and pneumonia which are prevalent in poor communities. [13].

Therefore ideal breast feeding practices have greatest potential for improving child survival and reducing inequity in Child mortality. As it also has impact on malnutrition it can have greater impact in poorer communities.

\section{Why is Breast Feeding Low in Developing Countries?}

Several studies have tried to look at the constrains of breast feeding and the finding in most have been similar.

Suresh et al. [14] in their study hypothesized that breast feeding problems were major contribution for breast feeding failure. They aimed to determine the breast feeding problems in first postnatal week, their predictors and impact on EBF at 6 month of age. Under a prospective cohort design, 400 mother infant dyad were assessed for breast feeding before discharge and at $60 \pm 12$ hours of discharge. Although $89 \%$ of mother infant had some breast feeding problem during the period of study, at six month of age breast feeding problem did not predict EBF.

In Lebanon where breast feeding rate is extremely low (4.1-10.1\%), Nabulsi et al. [15] found negative breast feeding experiences, negative perception of breast feeding whether at personal, family or society levels, misconceptions like insufficiency of breast milk to fulfill satiety in baby, breast feeding causing maternal weight gain or breast sagging etc. as the most important factors leading to early discontinuation of breast feeding. Many of the mothers who stopped breast feeding were found to be psychologically unprepared for breast feeding associated pain, sleep deprivation, exhaustion or other changes in life. The difficulties were compounded by maternal employment, poor family support or lack of professional advice.

Patel et al. [9] in their study found that the factors associated with lack of adequate EBF were less consistent across the regions than the factors associated with failure to achieve early initiation of breast feeding. The only factor which was consistent for the failure of EBF in all regions was multiple pregnancies. However they found that many other factors which they had examined had a significant relationship in sites of one or more regions and that these needed to be understood in the local context. For Example, in Guatemala, several factors including low education, being delivered by trained birth attendants were protective against failure to achieve EBF at 42 days postnatal.

Their study also highlighted the importance of early initiation of breast feeding to increase rate of exclusive breast feeding.

In their study Patel et al. [9] found that lower birth weight was a risk factor for both lack of early initiation of breast feeding and also mortality due to infection. They found that sicker and smaller babies were more often likely to have poor early initiation of breast feeding and EBF. Their study confirmed that factors like nulliparity, delivery by caesarian section, male gender, multiple birth, need for resuscitation are risk factors for poor EIBF and EBF (Figure 1).

\section{Is there a Way for Improving Breast Feeding Rate in Developing Countries?}

Haroon et al. [16] reviewed breast feeding promotion, intervention and breast feeding practices in 2013. They included 110 studies in the systematic review. A total of 66 studies were included to find out impact of intervention on exclusive breast feeding. Twenty seven of these 66 studies were conducted in developing countries. They found that overall educational interventions significantly increased EBF rates at day 1 by $43 \%$, (RR $1.43,95 \%$ CI $1.09-1.87$ ) at $<1$ month by $30 \%$ (RR $1.30,95 \%$ CI $1.19-1.42$ ) and at $1-5$ months by $90 \%$ (RR $1.90,95 \%$ CI $1.53-2.34)$.

They found that individual counseling alone led to an increase on day 1 to $60 \%$ (RR $1.695 \%$ CI 1.04-2.48) while the efforts of group counseling alone were non-significant. In developing countries these interventions led to an increase by $157 \%$ (RR2.57, 95\% CI 1.39-4.77) whereas a non significant effect was demonstrated in developed countries.

Facility based intervention were found to increase EBF rate by $26 \%$ (RR 1.26, 95\% CI 1.11-1.43) and combined with community based intervention it improved EBF rated by $31 \%$. This effect was significant for both developing and developed countries.

A Cochrane review [17] is available on antenatal education for increasing breast feeding duration, which examined specific types of breast feeding education and compared multiple methods with single method of education. Peer counseling, lactation counseling and formal breast feeding education during pregnancy were found to increase breast feeding duration.

All these evidences conclude that educational interventions increase EBF rate, initiation duration and exclusivity. Combined individual and group interventions were superior to individual or group counseling alone. Impact was higher in developing countries than in developed countries (Figures 2 and 3).

\section{What Type of Education Needs to be Provided to Antenatal Mothers?}

Although it is identified that antenatal and postnatal education of mothers improves breastfeeding rate, there can be certain barriers prevalent in a community which can hinder the efficacy of maternal education on breast feeding rate. Structured classes may be costly for some communities while some contents of educative material may not be culturally acceptable to some. Hence in each community these barriers need to be identified and plan should be made by government and health boards to assess and plan for improving access to antenatal education of mothers (Figures 1 and 2). 
Citation: Bora R (2016) Breast Feeding in Developing Countries: Is There a Scope for Improvement. J Neonatal Biol 5: 208. doi:10.4172/21670897.1000208

\begin{tabular}{|c|c|c|c|c|c|}
\hline Study or subgroup & $\begin{array}{r}\text { Formal BF education } \\
n / N\end{array}$ & $\begin{array}{r}\text { Routine care } \\
\mathrm{n} / \mathrm{N}\end{array}$ & $\begin{array}{c}\text { Risk Ratio } \\
\text { M-H,Fixed,95\% CI }\end{array}$ & Weight & $\begin{array}{r}\text { Risk Ratio } \\
\text { M.H,Fixed,95\% CI }\end{array}$ \\
\hline \multicolumn{6}{|c|}{ I BF education workshop versus routine care } \\
\hline Kluka 2004 & 29/96 & 22/82 & & $100.0 \%$ & $1.13[0.70,1.80]$ \\
\hline Subtotal $(95 \% \mathrm{CI})$ & 96 & 82 & & $100.0 \%$ & $1.13[0.70,1.80]$ \\
\hline \multicolumn{6}{|c|}{ Total events: 29 (Formal BF education). 22 (Routine care) } \\
\hline \multicolumn{6}{|c|}{ Heterogeneity not applicable } \\
\hline \multicolumn{6}{|c|}{ Test for overall effect $Z=0.50(P=0.62)$} \\
\hline \multicolumn{6}{|c|}{$2 \mathrm{BF}$ practical skills versus routine care } \\
\hline Forster 2004 & $26 / 297$ & 222299 & & $100.0 \%$ & $1.19[0.69 .2 .05]$ \\
\hline Subtotal $(95 \% \mathrm{CI})$ & 297 & 299 & & $100.0 \%$ & $1.19[0.69,2.05]$ \\
\hline \multicolumn{6}{|c|}{ Total events: 26 (Formal BF education). 22 (Routine care) } \\
\hline \multicolumn{6}{|c|}{ Heterogeneity, not applicable } \\
\hline \multicolumn{6}{|c|}{ Test for overall effect $Z=0.63(P=0.53)$} \\
\hline \multicolumn{6}{|c|}{3 Formal $\mathrm{BF}$ attitude versus routine care } \\
\hline Forster 2004 & $25 / 293$ & $222 / 299$ & & $100.0 \%$ & $1.16[0.67 .201]$ \\
\hline Subtotal $(95 \% \mathrm{CI})$ & 293 & 299 & & $100.0 \%$ & $1.16[0.67,2.01]$ \\
\hline \multicolumn{6}{|c|}{ Total events: 25 (Formal BF education). 22 (Routine care) } \\
\hline \multicolumn{6}{|c|}{ Heterogeneity. not applicable } \\
\hline Test for overall effect: $Z=$ & $(P=0.60)$ & & & & \\
\hline
\end{tabular}

Figure 1: Comparison of breastfeeding education vs. routine care, outcome of exclusive breast feeding at 6 months of age [17].

\begin{tabular}{|c|c|c|c|c|c|}
\hline Study or subgroup & Multiple interventions & Single intervention & $\begin{array}{c}\text { Risk Ratio } \\
\text { M- } \\
\text { H,Random,95\% } \\
\text { a }\end{array}$ & Weight & $\begin{array}{c}\text { Risk Ratio } \\
\text { M- } \\
\text { H.Random,95\% } \\
\mathrm{Cl}\end{array}$ \\
\hline \multicolumn{6}{|c|}{ I $L C+$ routine $B F$ education versus routine $B F$ education } \\
\hline Serwint 1996 & $31 / 74$ & $22 \pi 0$ & $\vdash$ & $100.0 \%$ & $1.33[0.86,2.07]$ \\
\hline Subtotal $(95 \% \mathrm{CI})$ & 74 & 70 & - & $100.0 \%$ & $1.33[0.86,2.07]$ \\
\hline \multicolumn{6}{|c|}{ Total events: 31 (Multiple interventions), 22 (Single intervention) } \\
\hline \multicolumn{6}{|c|}{ Heterogeneity. not applicable } \\
\hline \multicolumn{6}{|c|}{ Test for overall effect: $Z=1.29(P=0.20)$} \\
\hline
\end{tabular}

Figure 2: Comparison of single vs. multiple session of breast feeding education and effect on initiation of breast feeding [17].

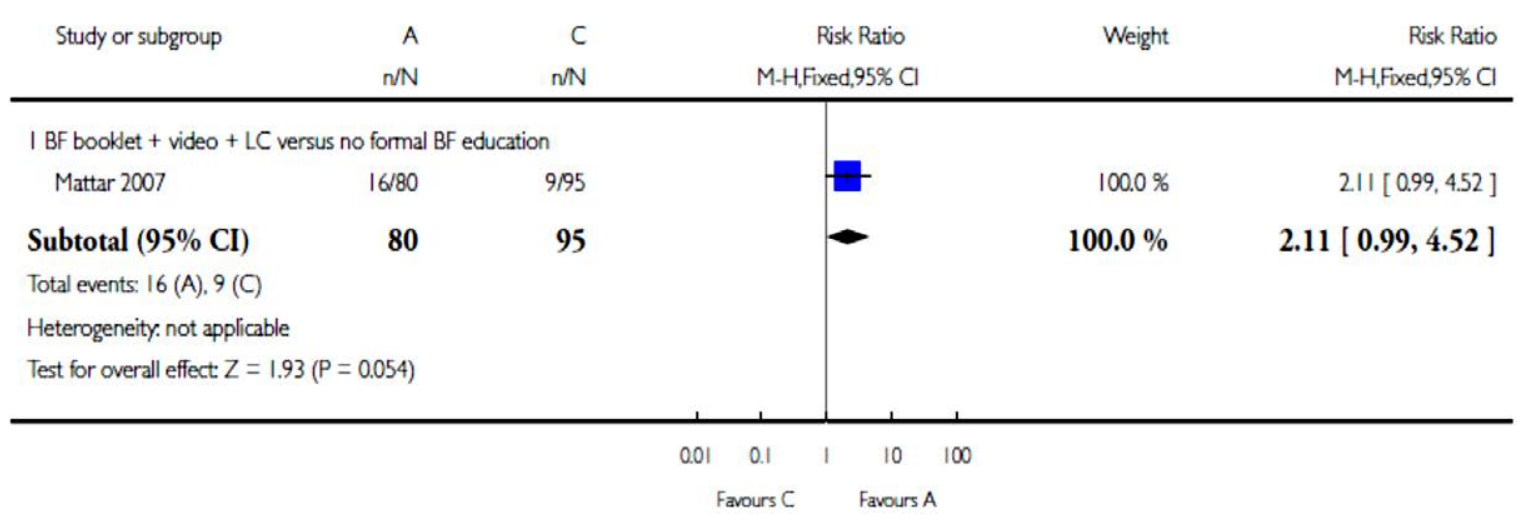

Figure 3: Comparison of multiple educational intervention vs. no formal education on exclusive breast feeding rates at six months of age [17]. 


\section{Type of antenatal education}

Forster and Mc Lachian [18] mentioned that outcomes of breast feeding was significantly improved if mothers delivered their babies in a baby friendly hospital where ten steps of breast feeding are implemented. Grguric found that if WHO recommendations were made known to mothers antenatally, they were $26 \%$ more likely to initiate breast feeding and $34 \%$ less likely to stop breast feeding once initiated [19].

Noel-Weiss conducted a randomized controlled trial of a prenatal breast feeding workshop to specially enhance confidence and measured the breastfeeding success rate in participants comparing them to controls at four and eight weeks post partum. Attendees of the workshop had more exclusive breast feeding (70\% vs. $58 \%$ ) and less weaning ( $15 \%$ vs. $22 \%$ ) compared with control group [20]. These evidence suggest positive effect of antenatal education on initiation and continuation of breast feeding.

\section{WHO recommendations of ten steps for successful breast feeding}

1. Have a written policy that is communicated to all health care staff.

2. Train all health care staff in skills necessary to implement this policy.

3. Inform all pregnant women about the benefits and management of breast feeding

4. Help mothers to initiate breast feeding within half an hour of birth.

5. Show mothers how to breastfeed, and how to maintain lactation even if they should be separated from their infants.

6. Give newborn infants no food or drink other than breast feeding unless medically indicated.

7. Practice rooming in that is, allow mothers and infants to remain together, 24 hours a day.

8. Encourage breast feeding on demand.

9. Give no artificial teats or pacifier (also called dummies or soothers) to breastfeeding infants.

10. Foster the establishment of breastfeeding support groups and refer mothers to them on discharge from hospital or clinic.

\section{Timing, delivery and format of antenatal education}

The variables of timing, delivery and format seems to have important impact on effectiveness of antenatal education on breast feeding initiation and continuation. Some researchers have observed that breast feeding promotion and emphasis on its health benefits if done early in pregnancy, have the maximum beneficial effect [21]. Beake et al. found that structured programs compared to standard care positively influenced the initiation and duration of exclusive breastfeeding or any breastfeeding specially in areas of low breast feeding rates [22]. Similarly length of the course, whether it is an individual or in group is an important variable for success. Researchers have concluded that longer courses have higher success rate [23]. However some others [24] in their studies in Asian countries have found that even one encounter of antenatal education and counseling is effective in improving knowledge, attitude and breast feeding practices.

Targeting non pregnant adolescents through electronic media with breast feeding education before pregnancy can be another method for increasing breast feeding rate. Apart from mothers, fathers should also be involved in education and decision making [25]. Many researchers have found fathers education to have significant influence in breast feeding success [26].

All these studies actually supports the idea that breastfeeding is a socially learned behavior and is a social decision. If the adolescents are not exposed to breast feeding role models, breast feeding rate may be low in a community [27].

\section{Postnatal support}

Another intervention which have been proved to be beneficial in increasing EBF rate is postnatal support There are evidences that effectiveness of antenatal education on improving breast feeding rate is enhanced by post natal education. Hannula et al. found [28] that multiple methods of postnatal support and education was more successful than using single method. Support from peer and other family members in the postnatal period is very important specially in the developing countries.

These interventions would depend on workforce which may be lacking in areas mostly needed i.e. in the developing countries. Counseling intervention administered by community health workers requires sufficient remuneration, such conditions may not be prevailing in the developing countries.

Roberts et al. [12] had also indicated role of legislative changes and the media in encouraging and supporting breast feeding. Legislative support for breast feeding at public places, breast feeding friendly work place policies, strict standard on content and advertisement of baby food are other interventions very important in low income countries. Availability of breast milk banking can be another method for increasing breast milk feeding .It is important to understand however that improving breast feeding rate do not rely mostly on technology but on grass root initiatives.

\section{Conclusion}

1. Although breast feeding has been known to improve child survival, still breast feeding rate in the community specially in developing countries has not become optimal during the past decade.

2. It is not adequate to initiate breast feeding but mother need to continue exclusively breast feed their babies till six months of age to improve their survival.

3. Breast feeding education and support increase breast feeding rates. Combined individual and group, structured education of mothers started early in pregnancy seem to be the best method of improving breast feeding rate at this time.

4. This intervention also has greater impact on developing countries where it is mostly needed.

\section{References}

1. National guideline on of infant and young child feeding (2004) Ministry of human resource development, Department of women and child development (Food and Nutrition Board) Government of India.

2. Arifeen S, Black RE, Antelman G, Baqui A, Caulfield L, et al. (2001) Exclusive breastfeeding reduces acute respiratory infection and diarrhea deaths among infants in Dhaka slums. Pediatrics 108: E67.

3. Brown KH, Black RE, Lopez de Romaña G, Creed de Kanashiro H (1989) Infant-feeding practices and their relationship with diarrheal and other diseases in Huascar (Lima), Peru. Pediatrics 83: 31-40. 
Citation: Bora R (2016) Breast Feeding in Developing Countries: Is There a Scope for Improvement. J Neonatal Biol 5: 208. doi:10.4172/21670897.1000208

Pge 5 of 5

4. Lozano R, Wang H, Foreman KJ, Rajaratnam JK, Naghavi M, et al. (2011) Progress towards Millennium Development Goals 4 and 5 on maternal and child mortality: an updated systematic analysis. Lancet 378: 1139-1165.

5. Jones G, Steketee RW, Black RE, Bhutta ZA, Morris SS, et al. (2003) How many child deaths can we prevent this year? Lancet 362: 65-71.

6. Bhutta ZA, Chopra M, Axelson H, Berman P, Boerma T, et al. (2010) Countdown to 2015 decade report (2000-10): taking stock of maternal, newborn, and child survival. Lancet 375: 2032-2044.

7. UNICEF (2006) Progress for Children: A Report Card on Nutrition.

8. NFHS-3 (2005) International Institute for Population Sciences (IIPS) and Macro International.

9. Patel A, Bucher S, Pusdekar Y, Esamai F, Krebs NF, et al. (2015) Rates and determinants of early initiation of breast feeding and exclusive breast feeding at 42 days postnatal in six low and middle-income countries: A prospective cohort study. Reproductive Health 12: S10.

10. Cai X, Wardlaw T, Brown DW (2012) Global trends in exclusive breastfeeding. Int Breastfeed J 7: 12.

11. Countdown to 2015. Maternal, Newborn and Child Survival: The 2012 Report. WHO and UNICEF.

12. Roberts T, Carnahan E, Gakidou E (2013) Can breastfeeding promote child health equity? A comprehensive analysis of breastfeeding patterns across the developing world and what we can learn from them. BMC Med 11: 254-255.

13. Rudan I, Boschi-Pinto C, Biloglav Z, Mulholland K, Campbell H (2008) Epidemiology and etiology of childhood pneumonia. Bull World Health Organ 86: 408-416.

14. Suresh S, SharmaK, Saksean M, Thukral A, Agarwala R, et al. (2014) Predictors of Breastfeeding Problems in The First Postnatal Week and Its Effect on Exclusive Breastfeeding Rate at Six Months. Experience in A Tertiary Care Centre in Northern India. Indian Journal of Public Health 58: 270-273.

15. Nabuls Mi (2011) Why are breastfeeding rates low in Lebanon?a qualitative study. Pediatrics 11: 75-76.

16. Haroon S, Das JK, Salam RA, Imdad A, Bhutta ZA (2013) Breastfeeding promotion interventions and breastfeeding practices: a systematic review. BMC Public Health 13 Suppl 3: S20.

17. Lumbiganon P, Martis R, Laopaiboon M, Festin M, Ho J, et al. (2011) Antenata breastfeeding education for increasing breastfeeding duration. Cochrane Pregnancy and Childbirth Group 11: CD006425.

18. Forster DA, McLachlan HL (2007) Breastfeeding initiation and birth setting practices: a review of the literature. J Midwifery Womens Health 52: 273-280.

19. Grguric J, Wen RA, Kylberg E, Ashmore S, Macenroe T (2012) International perspective of the baby Friendly Initiative . J of Human Lactation: Official journal of international lactation Consultant Association 28: 281-284.

20. Weiss N, Joy (2005) Effect of Prenatal education on Maternal breast feeding Efficacy and Breast Feeding duration (Masters Science), uO Research.

21. Jiang H, Li M, Yang D, Wen LM, Hunter C, et al. (2012) Awareness, intention, and needs regarding breastfeeding: findings from first-time mothers in Shanghai, China. Breastfeed Med 7: 526-534.

22. Beake S, Pellowe C, Dykes F, Schmied V, Bick D (2012) A systematic review of structured compared with non structured breast feeding programs to support the initiation and duration of exclusive and any breast feedingin acute and primary health care settings. Maternal and child nutrition 8: 141-161.

23. Dyson L, McCormick F, Renfrew MJ (2005) Interventions for promoting the initiation of breastfeeding. Cochrane Database Syst Rev : CD001688.

24. Artieta-Pinedo I, Paz Pascual C, Grandes G, Bacigalupe A, Payo J, et al. (2013) Antenatal breast feeding and in a cohort of Primiparas. J Adv Nurse 69: 1607-1617.

25. Alexander A, O'Riordan MA, Furman L (2010) Do breastfeeding intentions of pregnant inner-city teens and adult women differ? Breastfeed Med 5: 289-296.

26. Goulet C, Lampron A, Marcil I, Ross L (2003) Attitudes and subjective norms of male and female adolescents toward breastfeeding. J Hum Lact 19: 402-410.

27. Giles M, Connor S, McClenahan C, Mallett J, Stewart-Knox B, et al .Measuring young peoples attitudeto breast feeding using the Theory of Planned Behaviour. $\mathrm{J}$ of Public Health 29: 17-26.

28. Hannula L, Kauononen M, Tarkka MT. A systemic review of professional support interventions for breast feeding. J Clin Nurs 17: 1132-1143. 